\title{
Differences in aerosol output and airways responsiveness between the DeVilbiss 40 and 45 hand held nebulisers
}

\author{
C J Hartley-Sharpe, H Booth, D P Johns, E H Walters
}

\begin{abstract}
Background - The DeVilbiss 40 glass hand held nebulisers have been widely used for airways responsiveness testing in epidemiological surveys of asthma. These nebulisers have been superseded in some recent studies by the DeVilbiss 45 plastic hand held nebulisers with the assumption that they are interchangeable. This study compared the aerosol outputs of the DeVilbiss 40 and DeVilbiss 45 nebulisers and investigated whether there was any difference in the in vivo measurements of airways responsiveness when using the two nebuliser types.
\end{abstract}

Methods - The aerosol output of six DeVilbiss 40 and six DeVilbiss 45 nebulisers was calculated by weight loss per actuation, the usual method of calibrating nebuliser output, and compared with the true amount of aerosol obtained measured by a fluoride tracer technique. Airways responsiveness was measured twice in 13 asthmatic patients under identical conditions by the Yan protocol using DeVilbiss 40 and 45 nebulisers in random order.

Results - Weight loss overestimated the true aerosol output of both types of nebulisers. Weight loss was similar for the DeVilbiss 40 and 45 nebulisers but the true aerosol output of the DeVilbiss 45 was nearly twice that of the DeVilbiss 40 nebuliser. The geometric mean $\mathbf{P D}_{20}$ values with the DeVilbiss 40 nebuliser was a mean 1.7 doubling doses of histamine higher than that obtained with the DeVilbiss 45 nebuliser.

Conclusions - The Devilbiss 40 and 45 nebulisers should not be used interchangeably for airways responsiveness testing merely because their outputs based on weight loss are similar. Artefactual differences in the prevalence rates of airways responsiveness could occur in longitudinal studies if a change was inadvertently made from using DeVilbiss 40 to DeVilbiss 45 nebulisers.

(Thorax 1995;50:635-638)

Keywords: DeVilbiss nebulisers, nebuliser output, airways responsiveness.

In the absence of an agreed definition of asthma, studies to examine the prevalence of asthma in the community have emphasised measurement of airways reactivity as an ob-

jective test of the presence of asthma. ${ }^{1-3}$ How- ever, the ability to compare the prevalence of rates of asthma between different areas - for example, rural versus urban communities and longitudinally requires the equipment and protocols used to measure airways reactivity to be well standardised.

An essential component of standardisation is ensuring that the dose of provoking agent generated by the aerosol delivery system is measured accurately and is reproducible. This is traditionally calculated from the weight loss per actuation. ${ }^{1-4}$ It has been shown, however, that weight loss significantly overestimates the solute output of a number of different jet nebulisers, due mainly to concomitant evaporative water loss. ${ }^{5-7 .}$

There are a number of different aerosol delivery systems available. The Yan et al protocol ${ }^{8}$ has been widely used in field studies of asthma because of its brevity and portability of equipment. ${ }^{2910}$ This protocol uses the glass hand held DeVilbiss 40 nebuliser to generate aerosol. Some recent studies have substituted the plastic hand held DeVilbiss 45 nebulisers ${ }^{11} 12$ and have assumed that the two types of hand held DeVilbiss nebuliser are interchangeable because their output, measured by weight loss, is similar.

We have compared the total output of both the DeVilbiss 40 and 45 nebulisers measured by weight loss with the true aerosol output measured by a fluoride tracer technique. ${ }^{5}$ To test whether measured "true" output differences matter in field studies the clinical performance characteristics of the two nebuliser types was assessed by measuring airways responsiveness twice in stable asthmatic subjects under identical conditions, using DeVilbiss 40 and 45 nebulisers in random order.

\section{Methods}

NEBULISERS

The output of six new DeVilbiss 40 and DeVilbiss 45 nebulisers (DeVilbiss Health Care Inc) were measured by weight loss and the fluoride tracer technique on four and six occasions, respectively. Airways responsiveness was measured with the DeVilbiss 40 nebulisers numbered 1-4 (table 1) as their outputs were nearest to the mean. Similarly, the DeVilbiss 45 nebulisers numbered $1-4$ were used as their output, as measured by weight loss, fell within the $2-4 \mathrm{mg}$ limits suggested by Yan et al. ${ }^{8}$ All nebuliser actuations for calibration and airways responsiveness measurements were made by a single operator $(\mathrm{CJH})$ with the vent holes open.

\author{
Received 3 November 1994 \\ Returned to authors \\ 21 January 1995 \\ 2 March 1995 \\ Accepted for publication \\ 6 March 1995 \\ of Respiratory
Medicine, Alfed \\ University Medical \\ Victoria 3181 . \\ H Booth \\ E H Walter \\ Reprint requests to: \\ Reprint requests to:
Professor E H Walters.
}


Table 1 Weight loss and aerosol output characteristics of six DeVilbiss 40 and six DeVilbiss 45 nebulisers

\begin{tabular}{|c|c|c|c|}
\hline & $\begin{array}{l}\text { Weight loss } \\
(W L) \text { (mg) }\end{array}$ & $\begin{array}{l}\text { Aerosol output } \\
(A O)(\mathrm{mg})\end{array}$ & $\begin{array}{l}\text { Aerosol fraction } \\
(A O / W L \%)\end{array}$ \\
\hline $\begin{array}{l}\text { DeVilbiss } 40 \text { nebulisers } \\
\quad 1 \\
2 \\
3 \\
4 \\
5 \\
6 \\
\text { Mean (SD) }\end{array}$ & $\begin{array}{l}2 \cdot 77(0 \cdot 2) \\
2 \cdot 86(0 \cdot 2) \\
2 \cdot 83(0 \cdot 3) \\
3 \cdot 23(0 \cdot 2) \\
3 \cdot 65(0 \cdot 2) \\
3 \cdot 77(0 \cdot 2) \\
3 \cdot 18(0 \cdot 4)\end{array}$ & $\begin{array}{l}0.78(0.03) \\
0.78(0.02) \\
0.75(0.04) \\
0.99(0.03) \\
1.33(0.10) \\
1.31(0.06) \\
0.99(0.27)\end{array}$ & $\begin{array}{l}28 \cdot 2 \\
27 \cdot 3 \\
26 \cdot 5 \\
30 \cdot 7 \\
36 \cdot 6 \\
34 \cdot 7 \\
30 \cdot 7\end{array}$ \\
\hline $\begin{array}{l}\text { DeVilbiss } 45 \text { nebulisers } \\
\quad 1 \\
2 \\
3 \\
4 \\
5 \\
6 \\
\text { Mean (SD) }\end{array}$ & $\begin{array}{l}3.09(0.3) \\
3.84(0.3) \\
3.62(0.4) \\
2.98(0.3) \\
4.07(1.2) \\
4.70(0.7) \\
3.72(0.7)\end{array}$ & $\begin{array}{l}1.22(0.13) \\
1.74(0.17) \\
1.94(0.24) \\
1.35(0.13) \\
2.09(0.18) \\
2.30(0.07) \\
1.77(0.42)\end{array}$ & $\begin{array}{l}39 \cdot 5 \\
45 \cdot 3 \\
53 \cdot 7 \\
45 \cdot 3 \\
51 \cdot 4 \\
48 \cdot 9 \\
47 \cdot 3\end{array}$ \\
\hline
\end{tabular}

MEASUREMENT OF AEROSOL OUTPUT BY WEIGHT LOSS

Sodium chloride $(0.9 \%), 1 \mathrm{ml}$ or $3 \mathrm{ml}$, was placed in each of the DeVilbiss 40 and 45 nebulisers respectively. These volumes were used to ensure that the inlet tubes of each nebuliser type were covered. The vent holes were stoppered and the units weighed on a Mettler analytical balance to the nearest $0.01 \mathrm{mg}$. After removing the stoppers the bulb of each nebuliser was squeezed firmly 10 times. The stoppers were then replaced and the unit re-weighed. Weight loss per actuation was used to calculate aerosol output.

\section{MEASUREMENT OF AEROSOL OUTPUT BY} FLUORIDE TRACER TECHNIQUE

The principle of this technique for measuring the true solute output from nebulisers has been described in more detail elsewhere. ${ }^{5}$ Briefly, $1 \mathrm{ml}$ or $3 \mathrm{ml}$ of a $1 \% \mathrm{w} / \mathrm{v}$ sodium fluoride solution were placed in the appropriate nebulisers. The tip of the throat tube was placed just inside a $5 \mathrm{~cm}$ long plastic tube with an internal diameter of $3.7 \mathrm{~cm}$ which was used to represent their in vivo operating conditions. Each nebuliser was actuated 10 times and the generated aerosol per actuation entrained onto a $25 \mathrm{~mm}$ Whatman glass fibre filter (GF/A) paper held within an open faced filter holder (Nalgene 335-4000) at the end of the plastic tube through which air was being drawn by a vacuum pump at $24 \mathrm{l} / \mathrm{min}$. The filter paper was then removed and the fluoride desorbed overnight by soaking in an appropriate buffer. The quantity of fluoride collected on each filter paper was measured electrochemically and the true solute output per actuation calculated.

\section{PATIENTS}

Thirteen atopic mild asthmatic subjects (eight men; median age 28 years, range 20-45; two current smokers) had airways responsiveness measured on two separate occasions more than 48 hours apart. Each test was performed at the same time of day and at least eight hours after rescue $\beta_{2}$ agonist was given. Patients were allocated to have the first test with the DeVilbiss 40 or 45 nebuliser system in random order.
The study was approved by the Alfred Hospital ethical committee and all patients gave written informed consent to participate.

\section{MEASUREMENT OF AIRWAYS RESPONSIVENESS}

The protocol of Yan $e t a l^{8}$ was strictly followed. Spirometric parameters were measured with a calibrated Fleisch pneumotachograph (lung function analyser; Hewlett-Packard). Baseline spirometric values (forced expiratory volume in one second $\left(\mathrm{FEV}_{1}\right)$ and forced vital capacity (FVC)) were measured and repeated until the values of $\mathrm{FEV}_{1}$ and FVC were reproducible to within $100 \mathrm{ml}$. Nebuliser sets were primed with saline, $6.25 \mathrm{mg} / \mathrm{ml}, 25 \mathrm{mg} / \mathrm{ml}$, and $50 \mathrm{mg} / \mathrm{ml}$ histamine solutions. Inhalations were administered by placing the tip of the nebuliser throat tube just inside the open mouth and compressing the bulb at the beginning of maximal inspiration having started from slightly below functional residual capacity. Doubling doses of histamine were administered to subjects using 1-4 puffs within three minutes of the previous dose and spirometric tests were performed $30-60$ seconds later. The test was completed when a $20 \%$ decrement in $\mathrm{FEV}_{1}$ from post saline values had been achieved.

$\mathrm{FEV}_{1}$ was plotted against $\log _{10}$ cumulative dose to obtain the histamine $\mathrm{PD}_{20}$ by linear interpolation. Dose-response slopes (DRS) have been suggested to be a useful index of asthma severity ${ }^{13}$ and were calculated using the equation of Peat $e t a l^{14}$ as:

$$
\frac{\% \text { fall in } \mathrm{FEV}_{1} \text { at last dose }}{\text { total dose of histamine }(\mu \mathrm{mol})}+3
$$

\section{STATISTICAL ANALYSIS}

Outputs measured by weight loss and by the fluoride technique were compared for each nebuliser type by the paired Student's $t$ test. Comparison of the two types of DeVilbiss nebulisers was performed for each calibration method using the unpaired student's $t$ test.

All $\mathrm{PD}_{20}$ histamine levels and dose-response slopes were $\log _{10}$ transformed before statistical analyses and the results presented as geometric mean and standard deviations. The differences in $\mathrm{PD}_{20}$ and dose-response slope values for each individual measured by each nebuliser system were normally distributed and were therefore compared using the paired Student's $t$ test.

Double dose differences were calculated from the equation:

$\underline{\log _{10} \mathrm{PD}_{20} \text { (DV45 nebuliser) }-\log _{10} \mathrm{PD}_{20} \text { (DV40 nebuliser) }}$ $\log _{10} 2$

\section{Results}

MEASUREMENT OF NEBULISER OUTPUT

The mean output per actuation for the individual DeVilbiss 40 and 45 nebulisers calculated by weight loss and by the fluoride tracer method are shown in table 1. Mean weight loss significantly overestimated the true solute output by $321 \%$ and $210 \%$ for the DeVilbiss 40 and 45 nebulisers, respectively (both $\mathrm{p}<0.0001)$. 
Table 2 Airways responsivesness of 13 asthmatic subjects calculated as $P D_{20}$ and doseresponse slopes to histamine using DeVilbiss 40 or 45 nebulisers by the Yan protocol ${ }^{8}$

\begin{tabular}{|c|c|c|c|}
\hline & $\begin{array}{l}\text { DeVilbiss } 40 \\
\text { nebulisers }\end{array}$ & $\begin{array}{l}\text { DeVilbiss } 45 \\
\text { nebulisers }\end{array}$ & $p$ value \\
\hline $\begin{array}{l}\mathrm{PD}_{20}(\mu \mathrm{g}) \\
\text { Dose response slope }\left(\% \text { fall } \mathrm{FEV}_{1} / \mu \mathrm{mol}\right)+3\end{array}$ & $\begin{array}{r}272 \cdot 3(1 \cdot 5) \\
14 \cdot 6(1 \cdot 4)\end{array}$ & $\begin{array}{l}82 \cdot 8(1 \cdot 6) \\
36 \cdot 6(1 \cdot 7)\end{array}$ & $\begin{array}{l}<0.001 \\
<0.001\end{array}$ \\
\hline
\end{tabular}

Expressed as geometric mean (SD).

Aerosol output calculated by weight loss was not significantly different between the two types of nebuliser. However, output as measured by the fluoride tracer technique was significantly different, with the DeVilbiss 45 nebulisers generating on average $79 \%$ more solute than that produced by the DeVilbiss 40 nebulisers. This difference is emphasised by the ranges of true aerosol output: $0 \cdot 75-1.34 \mathrm{mg}$ for the DeVilbiss 40 and $1 \cdot 22-2 \cdot 30 \mathrm{mg}$ for the DeVilbiss $45 \mathrm{ne}-$ bulisers, which barely overlap.

\section{MEASUREMENT OF AIRWAYS RESPONSIVENESS}

The mean (SD) prechallenge $\mathrm{FEV}_{1}$ was not significantly different between the two study days: $3.86(0.92) 1$ and $3.75(0.92) 1$ for the DeVilbiss 40 and DeVilbiss 45 nebulisers respectively.

Table 2 shows the mean airways responsiveness measurements calculated as $\mathrm{PD}_{20}$ and dose-response slopes to histamine using both the DeVilbiss 40 and 45 nebulisers. The geometric mean $\mathrm{PD}_{20}$ value using the DeVilbiss 40 nebuliser system was a significant 1.7 doubling doses of histamine higher than with the DeVilbiss 45 nebulisers. In one patient the $\mathrm{PD}_{20}$ measured by both nebuliser systems was identical but in the remaining 12 patients the $\mathrm{PD}_{20}$ values were all higher using the DeVilbiss 40 than with the DeVilbiss 45 nebulisers and occurred across the wide range of airways hyperresponsiveness measured (figure).

The dose-response slopes were also significantly different between the two nebuliser types, being higher with the DeVilbiss 45 as might be expected from the above results.

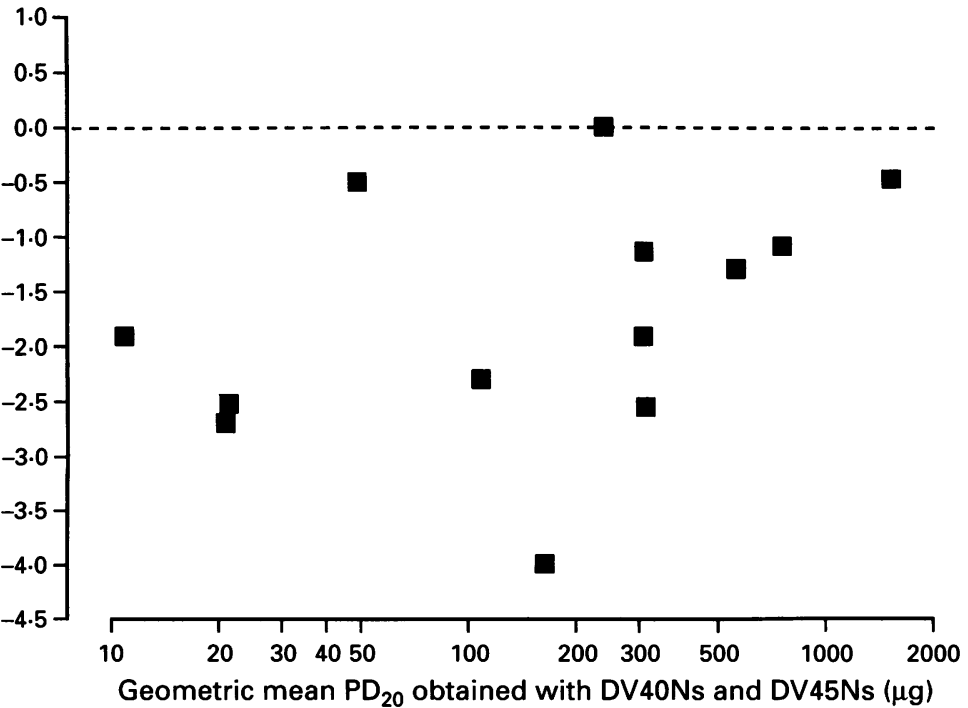

Differences in airways responsiveness measurements using DeVilbiss 40 and 45 nebulisers (DV40Ns and DV45Ns) by the Yan protocol ${ }^{8}$

\section{Discussion}

Nebuliser output has been shown to be one of the most important technical factors which affects the quantification of airways responsiveness. ${ }^{15}$ It is usually measured by weight loss per actuation but has been shown significantly to overestimate solute output for a number of different jet nebulisers. ${ }^{5-7}$ This difference is mainly due to evaporative water loss which occurs during nebulisation. Cockcroft et $a l^{7}$ estimated by indirect calculation from sodium lost during the actuation of a solitary DeVilbiss 40 nebuliser that true aerosol output was approximately $60 \%$ of weight loss per actuation. Detailed examination of the aerosol output of DeVilbiss 45 nebulisers has not been previously reported. Using the more sophisticated fluoride tracer technique developed by Dennis et $a l^{5}$ we have shown that the mean true aerosol output by the DeVilbiss 40 and DeVilbiss 45 nebulisers is $31 \%$ and $47 \%$ of weight loss, respectively.

Calibration by weight loss was performed in the standard way by weighing the nebuliser units before and after actuation into the room. However, these are not the precise conditions under which nebulisers are operated during airways responsiveness testing. The fluoride tracer technique more closely resembles this situation, with the vacuum pump representing a patient inspiring during nebuliser actuation. In this more realistic setting weight loss is increased by an average of $18 \%$ (personal observation) and the aerosol fraction would consequently be even further reduced.

Of perhaps more concern is the fact that the results of the present study suggest that the calibration of nebulisers by weight loss may actually be misleading. We have shown that although weight loss per actuation was not significantly different between the two types of DeVilbiss nebuliser, the DeVilbiss 45 generated almost twice as much active drug as the DeVilbiss 40 . This has important implications if it is assumed that the outputs, based on weight loss, are similar: (a) if the two nebuliser types are then used interchangeably for airway responsiveness measurements, and (b) if comparisons of different studies using the two different types of nebuliser are performed without taking this into account.

Having established that the aerosol outputs of the two types of DeVilbiss nebulisers were significantly different, the clinical part of the study was performed to determine if this was translated into a clinically significant difference in $\mathrm{PD}_{20}$ measurements. We have shown this to be the case with $\mathrm{PD}_{20}$ measurements being consistently higher with the DeVilbiss 40 nebulisers by a mean 1.7 doubling doses of histamine compared with the DeVilbiss 45 nebulisers. This difference is greater than we would expect based on the demonstrated output differences and probably reflects other differences in the performance characteristics of these two nebulisers - for example, droplet size. Certainly it has been reported that less than half of the output of the DeVilbiss 40 nebuliser is of a respirable size (less than $6 \mu \mathrm{m}$ mass median diameter ${ }^{16}$ ) and this proportion 
may well be different for the newer plastic DeVilbiss 45 nebuliser. That the difference in $\mathrm{PD}_{20}$ measurements between the DeVilbiss 40 and 45 nebulisers is more than a doubling dose difference is supported indirectly by a study by Knox et $a l^{17}$ which found that the geometric mean $\mathrm{PD}_{20}$ for the Yan et al method ${ }^{8}$ using DeVilbiss 40 nebulisers was $1 \cdot 14$ higher than with the Mefar dosimeter. It has previously been reported that the mean aerosol output of the Mefar nebuliser and dosimeter system using the fluoride tracer technique ranges from $50 \%$ to $76 \%$ of weight $\operatorname{loss}^{6}$ and is therefore comparable with our data for the DeVilbiss 45 nebuliser.

A change in airways responsiveness of a doubling dose of agonist is generally considered to be clinically significant. ${ }^{18}$ Indeed, most studies investigating the effects of glucocorticosteroids in asthma have reported changes of only 1-2 doubling doses. ${ }^{1920}$ Furthermore, this magnitude of difference in $\mathrm{PD}_{20}$ measurements between the two types of DeVilbiss nebuliser is likely to be an important confounder in longitudinal epidemiological asthma studies in which these different nebulisers have been used. Hence, in studies which classify subjects dichotomously into normal or hyperresponsive, more subjects are likely to attain a positive $\mathrm{PD}_{20}$ with the DeVilbiss 45 nebuliser than with the DeVilbiss 40 and this may, in part, explain the 1.4 fold and twofold increase in asthma prevalence rates which have been reported recently in Australian children in two towns over a 10 year period. ${ }^{11}$ Similarly, we have shown that analysis of data by calculating dose-response slopes is also affected by using the two different hand held DeVilbiss nebulisers. The practical importance of this is illustrated by the study of Toelle $e t a l^{12}$ which used DeVilbiss 45 nebulisers. A value of $9 \cdot 27 \%$ fall in $\mathrm{FEV}_{1} / \mu \mathrm{mol}+3$ was used as the upper limit of a normal dose-response slope but was based on a population sample using a DeVilbiss 40 nebuliser. ${ }^{14} \mathrm{~A}$ higher dose-response slope, which would have been more appropriate given the different DeVilbiss nebulisers used, would have been a better discriminator between those children with current asthma and those with a positive $\mathrm{PD}_{20}$ only.

In summary, measurement of weight loss per actuation significantly overestimates the true solute output of DeVilbiss hand held nebulisers. The aerosol fractions of the DeVilbiss 40 and 45 nebulisers are significantly different and this is reflected by higher $\mathrm{PD}_{20}$ measurements and lower dose-response slopes with the DeVilbiss 40 nebuliser.

For research purposes weight loss per actuation is therefore an inappropriate measure of nebuliser output and we would recommend the use of the fluoride tracer technique for this purpose. DeVilbiss 40 and 45 nebulisers should not be used interchangeably for testing airways responsiveness and caution is needed when comparing airways responsiveness rates and severity between studies which have employed these two different DeVilbiss hand held nebulisers. It will be important in future studies to specify which DeVilbiss nebuliser is being used for airways responsiveness testing.

1 Burney PGJ, Britton JR, Chinn S, Tattersfield AE, Papacosta AO, Kelson MC, et al. Descriptive epidemiology of bronchial reactivity in an adult population: results from a community survey. Thorax 1987;42:38-44.

2 Clifford RD, Radford M, Howell JB, Holgate ST. Prevalence of atopy and range of bronchial response to methacholine in 7 and 11 year old schoolchildren. Arch Dis Child 1989; 64:1126-32.

3 Peat JK, Haby M, Spijker J, Berry G, Woolcock AJ. Prevalence of asthma in Busselton, Western Australia. $B M \mathcal{F}$ valence of asthma

4 Sterk PJ, Fabbri LM, Quanjer PH, Cockcroft DW, O'Byrne $\mathrm{PM}$, Anderson SD, et al. Airways responsiveness. Standardised challenge testing with pharmacological, physical and sensitising stimuli in adults. Eur Respir f 1993;6(Suppl 16):53-83.

5 Dennis JH, Stenton SC, Beach JR, Avery AJ, Walters EH, Hendrick DJ. Jet and ultrasonic nebuliser output: use of a new method for direct measurement of aerosol output. Thorax 1990;45:728-32.

6 Dennis JH, Avery AJ, Walters EH, Hendrick DJ. Calibration of aerosol output from the Mefar dosimeter: implications of aerosol output from the Mefar dosimeter: implications

7 Cockcroft DW, Hurst TS, Gore B. Importance of evaporative water losses during standardized nebulized inhalation provocation tests. Chest 1989;96:505-8.

8 Yan K, Salome C, Woolcock AJ. Rapid method for measurement of bronchial responsiveness. Thorax 1983;38:760-5.

9 Britton J, Mortagny A, Tattersfield A. Histamine challenge testing: comparison on three methods. Thorax 1986;41: 128-32.

10 Peat JK, Woolcock AJ. Sensitivity to common allergens: relation to respiratory symptoms and bronchial hyperresponsiveness in children from three different climatic responsiveness in children from three different clim

11 Peat JK, van der Berg RH, Mellis CM, Leeder SR, Woolcock AJ. Changing prevalence of asthma in Australian children. $B M \mathcal{F}$ 1994;308:1591-6.

12 Toelle BG, Peat JK, Salome CM, Mellis CM, Woolcock AJ. Toward a definition of asthma for epidemiology. $A m$ Rev Respir Dis 1992;146:633-7.

13 O'Connor G, Sparrow D, Taylor D, Segal M, Weiss S. Analysis of dose-response slope to methacholine. An approach suitable for population studies. Am Rev Respir Dis proach suitable for

14 Peat JK, Salome CM, Berry G, Woolcock AJ. Relation of dose response slope to respiratory symptoms in a population of Australian schoolchildren. Am Rev Respir Dis 1991;144:663-7.

15 Ryan G, Dolovich MB, Obminski G, Cockcroft DW, Juniper $\mathrm{E}$, Hargreave FE, et al. Standardization of inhalation provocation tests: influence of nebuliser output, particle size, and method of inhalation. F Allergy Clin Immunol 1981;67:156-61.

16 Chan KN, Clay MM, Silverman M. Output characteristics of DeVilbiss No. 40 hand-held jet nebulizers. Eur Respir f 1990;3:1197-201.

17 Knox AJ, Wisniewski A, Cooper S, Tattersfield AE. A comparison of the Yan and a dosimeter method for methacholine challenge in experienced and inexperienced subjects. Eur Respir f 1991;4:497-502.

8 Fuller RW. Do prophylactic anti-asthma drugs alter airway hyperresponsiveness. In: Page CP, Gardiner PJ, eds. Air way hyperresponsiveness: is it really important for asthma? Oxford: Blackwell Scientific Publications, 1993:297-315

19 Kraan J, Koeter GH, van der Mark TW, Sluiter JH, de Vries $\mathrm{K}$. Changes in bronchial reactivity induced by four weeks of treatment with antiasthmatic drugs in patients with allergic asthma: a comparison between terbutaline with allergic asthma: a comparison between terbutaline

20 Jenkins CR, Woolcock AJ. Effect of prednisone and beclomethasone diproprionate on airway responsiveness in asthma: a comparative study. Thorax 1988;43:378-84. 